\title{
"ETNOLOGÍA E HISTORIA ANTIGUA DE CHILE". UNA CONFERENCIA INÉDITA DE MAX UHLE EN LA UNIVERSIDAD DE CHILE, 1914
}

\author{
“ETHNOLOGY AND ANCIENT HISTORY OF CHILE”. \\ AN UNPUBLISHED LECTURE BY MAX UHLE AT UNIVERSIDAD DE CHILE, \\ 1914
}

Jorge Pavez Ojeda ${ }^{1}$

\begin{abstract}
Presentamos aquí una conferencia inédita del arqueólogo andinista alemán Max Uhle (1856-1944), realizada en la Universidad de Chile el año 1914. En ella se exponen las principales tesis sobre la "historia antigua" de Chile que Uhle venía elaborando en sus tres años de residencia e investigación en el país, apoyado también en sus amplias investigaciones iniciadas en 1896 en las regiones centro y sur andinas. La conferencia da a conocer los elementos empíricos y teóricos que Uhle elabora para dar cuenta de la formación de las culturas del territorio "chileno", especialmente: la distinción entre evidencias antropométricas y civilizatorias, el uso de evidencias lingüísticas para el análisis cultural, la elaboración de secuencias temporales a partir de la comparación estilística, la aplicación de nociones difusionistas a los fenómenos de contacto histórico-cultural, y la identificación de dos tipos de "influencias" sobre las "naciones" del territorio ahora chileno (la de las "hordas" del Este y la de las "civilizaciones" del Norte), siendo estas últimas claramente diferenciadas en sus "horizontes" Tiahuanaco e Inca, lo que también le permite postular los "desarrollos regionales" propios del territorio.
\end{abstract}

Palabras claves: Max Uhle, Historia de la Arqueología, Prehistoria de Chile, Etnología y Arqueología.

This paper presents a transcription of an unpublished lecture given by the German Andean archaeologist Max Uhle (18561944) at Universidad de Chile in 1914. Here, Uhle presents his main assumptions on the ancient history of Chile, which he developed during his three years of residence and research in the country and which are also supported by his extensive research in the Central and Southern Andes. The lecture offers empirical and theoretical knowledge elaborated by Uhle to give account of the formation of cultures in the Chilean territory, namely: the distinction between anthropometric and civilizational evidence, the use of linguistic marks for cultural analysis, the development of time sequences from stylistic comparisons, the application of diffusionist notions to the phenomenon of historical and cultural contacts, and the identification of two types of "influences" on the nations of the current Chilean territory - "hordes" from the East and "civilizations" from the North, the latter being clearly distinguished by their Tiahuanaco and Inca "horizons", allowing him to postulate the idea of "regional developments" in the Chilean territory.

Keywords: Max Uhle, History of Archaeology, Prehistory of Chile, Ethnology and Archaeology.

El año 1914, el filólogo y arqueólogo andinista alemán Max Uhle (1856-1944) ofrece en la Universidad de Chile una serie de ocho conferencias sobre historia antigua americana. El programa de las conferencias con sus títulos y resúmenes fue publicado por la Imprenta Barcelona en Santiago, pero las conferencias mismas permanecieron inéditas. En la investigación que realizamos hace varios años sobre la historia de la antropología en Chile (Pavez 2015), accedimos al Fondo Uhle conservado en el Instituto Iberoamericano de Berlin, donde se encuentran resguardados los manuscritos de las conferencias, sin títulos, pero numerados del I al VIII. Gracias a la bibliografía de Rowe (1954:36) pudimos cotejar los manuscritos con el título y fecha de cada conferencia:

Vortrag I: 24 abril: "El origen del indio americano"; Vortrag II: 8 mayo: "Naciones y civilizaciones antiguas de México";

Vortrag III: 15 mayo; "Las regiones limítrofes entre

\footnotetext{
${ }^{1}$ Universidad de Tarapacá, Santiago, Chile. jorge.pavez.ojeda@gmail.com
}

Recibido: mayo 2019. Aceptado: abril 2020.

http://dx.doi.org/10.4067/S0717-73562021005000803. Publicado en línea: 20-junio-2021. 
América del norte y la del Sur: Centroamérica, Colombia, Venezuela y Ecuador";

Vortrag IV: 22 mayo: "Las tribus de las regiones tropicales del este";

Vortrag V: 29 de mayo: "Las naciones y civilizaciones antiguas del Perú";

Vortrag VI: 5 junio: "El imperio de los Incas";

Vortrag VII: 12 junio: "El este de Sud América al sur de los trópicos";

Vortrag VIII: 19 junio: "Etnología e historia antigua de Chile". Es esta última conferencia la que editamos en versión íntegra para su publicación en Chungara.

\section{Max Uhle en Chile}

Para el momento de esta serie de conferencias, Max Uhle había realizado varias de sus campañas arqueológicas en Calama, Constitución y Pisagua, lo que le permitía aspirar a establecer las bases para la investigación de la prehistoria chilena. Sin embargo, no había realizado aún las excavaciones en Arica que lo llevarían al descubrimiento de las momias Chinchorro y sus postulados sobre "los aborígenes de Arica y Tacna" (Uhle 1919).

Max Uhle se instala en Santiago a finales de 1911, y entre junio y agosto de 1912 realiza su primera campaña de excavación en Chile, en las localidades de Calama, Chiu-Chiu, San Pedro de Atacama y Lasana, con importantes hallazgos en el cementerio Chunchuri de Calama, de donde recupera más de 200 cráneos y momias y 1100 objetos antiguos (Dauelsberg 1995:372; Orellana 1996:101). A partir de esta recolección, que complementa con la importante donación de objetos que le hiciera Aníbal Echeverría Reyes de Anfofagasta, Uhle produce la primera colección arqueológica del Museo a su cargo ${ }^{1}$, y otorga las bases materiales para la definición de una Cultura Atacameña que, como veremos, va a constituir una matriz etnológica central para la elaboración arqueológica de una prehistoria "chilena".

En 1913, Uhle realiza dos importantes campañas. La primera entre mayo y septiembre, en la que recorre la costa norte, desde Coquimbo y Caldera hasta las localidades de Pisagua y Punta Pichalo, comentadas por Pedro Canales en el Congreso de Buenos Aires (1910), y en los textos de Blake y Latcham (1910). En todo este recorrido costero, Uhle intenta ubicar a los changos en tanto grupo étnico, como atestiguan los títulos de sus libretas de campo "Expedición a los Changos No.1 La Serena", "Expedición a los Changos No. 3 Pisagua", "Expedición Chango Sector SantiagoPaposo", "Expedición Chango Sector Taltal-Paposo" y "Expedición Chango 4ta." (Libretas 98, 99, 100, 101 y 102, en Dauelsberg 1995:378-380). Su excavación estratigráfica en tres cementerios y una cueva le permitirán pensar una secuencia cronológica para la macro-región del Desierto de Atacama. Ese mismo año, Uhle viaja al sur en compañía del Dr. Benavente, visitando la ciudad de Chillán, la localidad de Ninhue y realizando una excavación en Curahuen.

A principios del año 1914 realiza una campaña en Constitución, donde "descubre" la primera "estación paleolítica" del territorio chileno, hallazgos que informa el 28 de marzo ante la Sociedad Chilena de Historia y Geografía. Asimismo, entre el 24 de abril y el 19 de junio, ofrece la serie de ocho conferencias en la Universidad de Chile sobre "etnografía y arqueología de los países americanos desde México al sur". En lo que queda del año se dedicará a ordenar los materiales reunidos e intentar su interpretación, además de gestionar la infraestructura para la exhibición permanente del Museo de Etnología (Uhle, Libreta 109, IAI-Berlín). Es probablemente en ese año que redacta, en alemán y con caligrafía sütterlin (Sütterlinschrift), el manuscrito Changos und Pisagua, de casi 400 páginas aún inéditas, donde reúne su interpretación de los hallazgos costeros efectuados en esa oportunidad.

En enero de 1915, Uhle vuelve a viajar a Constitución, y excava un conchal en la hacienda Quivolco, confirmando su intuición de una "estación paleolítica", y prosiguiendo el debate en torno al problema paleolítico (Dauelsberg 1995:372-373; Erhardt 1998:108-109; Rowe 1954:3437). A finales de ese año, el contrato de Uhle es oficialmente revocado por el gobierno "por falta de fondos", por lo que se nombra a Aureliano Oyarzún como director ad honorem del Museo de Etnología y Antropología (Gusinde 1916:4). Lamentando la partida de Uhle, Oyarzún le solicita un último encargo oficial: realizar una excavación de control en el conchal de Taltal explorado por el juez de aduanas Augusto Capdeville, quien enviaba noticias de haber descubierto una estación paleolítica, y adjuntaba piezas líticas para demostrarlo (Uhle en Mostny 1964:4).

Uhle se queda veinte días durante mayo de 1916 en Taltal, iniciando una colaboración con Capdeville que durará más de 10 años y de la cual el epistolario entre ambos, editado por Grete Mostny (1964) es un exhaustivo registro. Nuevamente sin contrato laboral, entre julio 1916y 1918 Uhle se instala en la ciudad de Arica, donde establece su base para desarrollar excavaciones en Chinchorro, Azapa, Lluta, Tacna y Caplina, además del Morro y la Estación Sanitaria de la ciudad de Arica. Estos trabajos le permitirán completar definitivamente la secuencia cronológica que propone para la prehistoria del territorio chileno, tal como este había quedado conformado luego de la anexión de los vastos territorios del norte y del sur (Erhardt 1998:108-109). Además de esta elaboración científica que publicaría unos años después desde el Ecuador (Uhle 1919 y 1922), Uhle dejaba en Chile el acervo arqueológico del Museo de Etnología y Antropología, compuesto de más de 450 cráneos colectados por él (Âlvarez 1984), más de 50 
momias, 3.800 objetos, y 400 "cráneos de indios de razas extinguidas" (Gusinde 1916:3). Por eso, en su presentación del Museo de Etnología y Antropología, publicada en el primer número de la revista Publicaciones del Museo, Martin Gusinde reconoce la paternidad de Uhle sobre el proyecto, y aprovecha de adscribirlo a la tendencia dominante del momento en la etnología germana:

con su retiro pierde nuestro país al hombre más competente y preparado para estudios pre-históricos en Chile. Lo puedo asegurar, ya que durante tres años estuve trabajando con él y me honro de ser su discípulo. Aplicando el nuevo método (Kultur-historische Methode) de la Etnología moderna a nuestras investigaciones comunes, alcanzamos los resultados más halagüeños (Gusinde 1916:6).

Gusinde se inscribe así junto a Augusto Capdeville como uno de los primeros autoproclamados discípulos del arqueólogo alemán en Chile.

\section{El debate nacional de los problemas etnológicos americanos}

La estadía de Uhle en Chile parece gestarse en el Congreso de Americanistas realizado en Buenos Aires en 1910, al que el gobierno de Pedro Montt envía una importante delegación. La visita de los chilenos al Museo de Historia Natural de La Plata será clave para la decisión de impulsar la creación de un Museo Antropológico en Santiago. Inicialmente se pensó encargar esa tarea al italiano Aldobrandino Móchi, quien también participaba en el Congreso, pero luego de la muerte del presidente Montt se decide la contratación de Max Uhle, quien había dirigido en el mismo Congreso los debates de la Sección Arqueología y Etnología de Perú, Bolivia y Chile (Delegación Chilena 1910:902-904; LehmanNitsche 1912:103; Mora Nawrath 2016:117-118). Es en esta Sección que Aureliano Oyarzún intervino con la ponencia "Contribución al estudio de la influencia de la civilización peruana sobre los aborígenes de Chile", propuesta que vuelve sobre la cuestión de la influencia andina en las regiones del sur de Chile, en una discusión de post-guerra del Pacífico que estaba permeada por un proyecto historiográfico de nacionalización del pasado (Ganger 2011; Mac Evoy 2011). El título mismo anuncia los criterios exploratorios de la discusión que Max Uhle va a llegar a desentrañar: hasta entonces se hablaba de la "civilización peruana" para referirse al Imperio Inca, y de "los aborígenes de Chile" para referir principalmente a los araucanos o mapuche del sur (Oyarzún 1979:2744). Luego de presentar algunas consideraciones generales, Oyarzún analiza los vasos aríbalos y otros "vasos antiguos" encontrados en territorio chileno, para finalmente detenerse en la exposición de lo que llama "supervivencias", aplicando la noción evolucionista acuñada por Tylor (1871) a la cultura material de jarros, adornos de plata y textiles. De esta manera concluye "que la civilización prehispánica de Chile se deriva del Perú y los actuales araucanos conservan todavía por supervivencia los restos de aquella antigua civilización" (Oyarzún 1979:44).

Se trata aquí de una re-andinización de la prehistoria chilena $^{3}$, influencia que había sido cuestionada por la historiografía nacionalista desde la Guerra del Pacífico. Vicuña Mackenna por ejemplo, presentaba a la civilización incaica como despótica y usurpadora, mientras que Barros Arana reconocía una débil influencia del "pueblo peruano" sobre una población aborigen chilena que consideraba homogénea y extremadamente primitiva, totalmente carente de civilización (Ganger 2011:185-191; Latcham 1938:5). Mientras que Oyarzún defendía la existencia de una relevante influencia incaica y más generalmente peruana en las culturas de Chile, Ricardo Latcham retomando el discurso des-incaizador anunciaba "que la civilización incaica no tuvo influencias tan trascendentales en el desarrollo cultural de los indígenas chilenos como generalmente se ha creído" y "que en vez de la homogeneidad que se ha supuesto en la población indígena a la llegada de los españoles habría una heterogeneidad completa" (Latcham 1912:28-29).

La cuestión de la "raza araucana" se había vuelto especialmente importante para el imaginario nacionalista chileno luego de la Guerra del Pacífico y en las vísperas del Centenario de la República. Entre los productores de este imaginario destacó Nicolás Palacios (1904), que elabora una interpretación raciológica carente de consistencia empírica o científica. Los etnólogos chilenos como Oyarzún, Latcham o Guevara requerían entonces de investigaciones más sólidas que las afirmaciones de Vicuña, Barros o Palacios, sobre todo porque el problema de la influencia incaica era decisivo para las teorías que se quería sustentar sobre la cultura mapuche o "raza araucana". Es este tipo de investigaciones, basadas en teorías y evidencias arqueológicas, las que se esperaba podía proveer Max Uhle. Las expectativas sobre la llegada de Max Uhle parecían entonces importantes, ya que además de apoyar la formación y clasificación de las colecciones de un Museo de Etnología y Antropología, debía ayudar a resolver el sinnúmero de problemas etnológicos que se presentaban en Chile ante historiadores e ideólogos sin práctica arqueológica científica en sus pugnas por producir las bases históricas de la "raza chilena" (Pavez 2015:169-315).

Antes de su llegada a Chile, Uhle llevaba más de 15 años residiendo en el continente americano, con estadías de investigación, campañas de excavación y trabajo con colecciones en Argentina (1892-1893), Bolivia (18931896), Estados Unidos (1897 y 1901-1902) y Perú 
(1896-1901 y 1903-1911). Este recorrido implicará la definición y marcación fundacional del espacio arqueológico de la etnología andinista, en especial por una "hazaña intelectual de primer orden" de Uhle (Rowe 1998:18): la "introducción de la idea de tiempo" en base a las relaciones de estilos artísticos del Antiguo Perú, que le permiten proponer una secuencia temporal y una cronología relativa para la historia antigua de las civilizaciones andinas.

Apenas instalado en Chile, Uhle inicia las campañas arqueológicas que lo llevarán a formular sus principales tesis sobre la "etnología e historia antigua de Chile", como señala el título de la conferencia que presentamos aquí, realizada luego de dos años y medio de intenso trabajo. Para entonces Uhle ya tenía algunas conclusiones respecto al problema de la influencia andina entre las razas de Chile, las que, como era de esperar, trasladaron las preguntas que se hacían los chilenos hacia otras dimensiones del problema prehistórico. En esta conferencia hasta ahora inédita, se puede acompañar la lectura que hace Uhle de las investigaciones existentes en Chile al momento de su llegada, especialmente las de Medina, Latcham, Guevara y Lenz, por cuyos trabajos, dice, "se han ensanchado nuestros conocimientos sobre los tipos de las civilizaciones y lenguas antiguas, que facilitan extensamente la reconstrucción de la historia de las civilizaciones". Aquítambién toma posición respecto a los argumentos de Latcham, a quien cede algunos puntos y cuestiona directamente otros, especialmente aquel relacionado con la influencia andina. Y esto no podía ser de otra manera cuando vemos que para entonces Uhle parece estar convergiendo cada vez más decididamente con las teorías y modelos difusionistas, convergencia que hace explícita en una conferencia del año siguiente:

Según las nuevas teorías de Gräbner y Foy de Alemania y Guillermo Schmidt de Viena, ningún tipo de cualquier civilización alcanza un grado de civilización más alta sin haberse rozado con representantes de civilizaciones más altas, y haber sufrido la inundación [sic] por ellas. Considero que esta teoría en muchos sentidos no es más que un desarrollo de mi propio método de la comparación de civilizaciones hasta su última consecuencia. Pero mientras mi propio método revelaba solo las relaciones históricas que intervenían entre las civilizaciones de un distrito restringido, las nuevas teorías de Gräbner, Foy y Schmidt son capaces de ayudar más poderosamente en la revelación del origen de todos los innumerables tipos de civilización americana, y mundana (Uhle 1915c).

La comparación de civilizaciones en la historia antigua de Chile, Uhle la realizó en la conferencia que presentamos aquí, estableciendo dos tipos de influencias potenciales en la evolución civilizatoria de las "naciones" que habitaban la difícil geografía y medio ambiente de Chile: la de las "hordas intranquilas" y "turbulentas" que provenían siempre del este, y la de los "vecinos del norte" de donde llegaban las "ideas de progreso" y "elementos de civilización". La Cordillera de los Andes era concebida, ya no como un Volkertore o "zona de contacto" como los que destacaba su maestro Adolf Bastian (Bastian 1873, en Penny 2003:96), sino como protección y "defensa" para la formación de "naciones" y la evolución civilizatoria, aunque también podía contribuir a la "estagnación por falta de contacto continuo con naciones vecinas". Así, Uhle opta decididamente por la revaloración de la influencia del Antiguo Perú en la historia chilena, como agente de progreso y civilización anteriores a la conquista española.

De esta manera, Uhle maximizaba la extensión de la influencia incaica ("la influencia de todas las civilizaciones principales del antiguo Perú [...] con excepción de la primera de Proto Nazca") hasta al menos la región de Valdivia en el sur de Chile, considerando elementos cerámicos, textiles y linguísticos, extendiéndola mucho más que Medina (1882) quien la había percibido hasta Santiago, y dándole sustento a las tesis que Guevara (1924) explayaría más adelante. Por otra parte, la diferenciación entre el concepto bio-antropométrico de raza y el de nación (civilización o cultura) le permite rescatar y adherir a la "heterogeneidad antropológica" (en el sentido físico) postulada por Latcham (1912), observando que hay muchas formas antiguas y muchas formas anómalas de cráneos entre las colecciones osteológicas, y subrayando la frecuencia especial de dos tipos de cráneos, uno largo asociado a regiones periféricas, y otro corto asociado a regiones centrales. Dicho esto, Uhle restaura la diferencia e indeterminación entre un concepto físico y otro políticocultural de la población, acercándose de esta manera a la tesis de una mayor homogeneidad cultural postulada por Guevara: "Mucho menos variedad se encuentra en el tipo de las naciones que entre los tipos antropológicos que desde tiempo muy antiguo se encuentran en el suelo chileno". Ofrecen así una visión multirracial de las naciones chilenas. Para establecer un posible origen de los araucanos, Uhle observa las semejanzas lingüísticas con los gés de Amazonía, y propone el noreste como su hogar de origen: "Con esos inmigrantes llegó al país un elemento fuerte y robusto y de costumbres sanas que, separado de las turbulencias de las naciones del este, bien pudo formar una base para un desarrollo de la civilización del país". Pero Uhle, seguro de su conocimiento de las principales civilizaciones del centro andino, instala un horizonte civilizatorio anterior al Inca, que sería el que primero irradió su cultura a ese "elemento fuerte y robusto y de costumbres sanas", piso sobre el cual habría venido luego a sobreponerse la civilización incaica: "A las influencias 
de la civilización de Tiahuanaco se debe en todo el sur la introducción del arte de tejer y teñir, y la domesticación del llama" [sic]. Esta influencia de Tiahuanaco habría llegado hasta Chiloé e incluyó también la agricultura de la papa, y ciertos elementos linguiísticos como la sub-fijación, que calcula más reciente en el mapudungun que en el quechua o el aymara (el que asume como la lengua de Tiahuanaco), y que considera como elemento de civilización proveniente del norte, y no del este donde no se habrían conocido estos "adelantos" lingüísticos. A su vez, como observa ciertas correspondencias culturales entre los valles de CopiapóOvalle y el Río Maipo, asume que "los Araucanos del Sur y los Diaguitas del Norte se penetraron mutuamente en una región limítrofe"'. Luego de estos análisis y fiel a su modelo de difusión (contra la invención cultural autónoma), reitera la importancia de la influencia incaica sobre los araucanos:

Con mucha inteligencia los araucanos adoptaron detalles vistos en objetos de la civilización de los Incas, aunque esa [misma] nunca llegó [por] conquistas militares hasta el último sur, y esa observación a mi parecer vale más que vindicar a su propia invención progresos que no podrían haber hecho por sí mismos, y tarde o temprano aparecerían como debidas a enseñanzas forasteras. Todo eso prueba que a la nación araucana nunca faltaba una buena porción de inteligencia natural, solo le faltaron por un número de siglos los maestros que la condujeran a la civilización (Uhle 1914, el destacado mío).

Las campañas de Taltal, Pisagua, Arica y Tacna le permitirán terminar de definir la historia antigua de Chile en términos crono-topológicos. Pareciera que cada campaña fue dando claves para "resolver problemas" -como gustaba decir-, de orden temporal o territorial, dando origen y sustento a las definiciones etnológicas de: (1) los atacameños como matriz cultural y polo de desarrollo civilizatorio regional específico, separado de sus vecinos bolivianos y peruanos, y que los chilenos podrían entonces considerar como "propios"; (2) los changos, como grupo definido por la actividad pesquera, esparcido por la costa norte recién conquistada, casi invisible en términos etnológicos pero que permite separar conceptualmente la región costa del interior cordillerano; (3) el hombre primordial de las "estaciones paleolíticas" (de Taltal y Constitución), como Ur-Volk a partir del cual se iniciaba toda la secuencia temporal post-glacial en la larga geografía chilena; (4) los aborígenes de Arica, base del particularismo de un Volkertore que permitía instalar una cuña regionalista en la disputa fronteriza entre Perú y Chile (Pavez 2015:180-256).

Los aportes de Uhle darán impulso al debate chileno, donde luego de su partida se enfrentaron dos grandes tesis: la de Ricardo Latcham $(1912,1925)$ sobre una completa heterogeneidad cultural y racial en el territorio chileno, donde la civilización araucana se habría formado por la llegada de una población oriental, inserta en forma de cuña en un sustrato poblacional anterior de "mayor civilización”, y la de Tomás Guevara (1924), que defendía la homogeneidad de una población considerada araucana desde Copiapó hasta Chiloé, la cual se habría desarrollado tardíamente gracias a la influencia inca. Mientras Guevara maximaliza las propuestas de Uhle, Latcham propone interpretaciones de los hallazgos empíricos del arqueólogo alemán para reforzar su propia tesis (Parentini 1996, González Pizarro 2014).

Max Uhle no guardará un buen recuerdo de su experiencia en Chile, lo que resalta en varias cartas de su correspondencia con colegas o discípulos. En 1920, le comenta desde Quito a Eric Boman: "Chile en términos generales me ha tratado miserablemente a mí, a mis esfuerzos, a mi intento de organización del museo en los años 1912-16" (11 septiembre 1920, en Nastri 2010:44). Al año siguiente, desde Cuenca, le escribe a Augusto Capdeville luego del fallecimiento de su esposa: "Si hubiese tenido experiencias oficiales más agradables, o primero en Lima o después en Santiago, no habría habido la necesidad de que mi señora fuera a Alemania donde las consecuencias de la guerra la han llevado tan horrorosamente a la tumba. ¡Así son los destinos! Ahora estoy estudiando solo los problemas, con mucho menos valor y ánimo para la vida" (30 de diciembre 1921, en Mostny 1964:156). Unos años después, en nota final a una carta al mismo Capdeville, su juicio se extiende a la "arqueología chilena": "Mucho siento que la situación de la arqueología chilena está ahora en condiciones lamentables" (22 de octubre 1926, en Mostny 1964:178). La posteridad ha sido más generosa con Uhle, destacando sus aportes a la fundación de la arqueología, especialmente sus propuestas de secuencias temporales y cronologías relativas, su identificación de las culturas locales como "desarrollos regionales", y su hallazgo y descripción de las "momias Chinchorro" (Álvarez 1974; Allison et al. 1984; Arriaza 1995, 2005; Llagostera 2003; Mostny 1964; Nuñez 2010; Orellana 1996; Rivera 1974, 1995; Santoro et al. 2010). Esperamos que la publicación de esta conferencia inédita contribuya a la valoración póstuma de una narrativa etnológica fundadora de la arqueología andina.

\section{Trascripción del Manuscrito "Etnología e historia antigua de Chile", conferencia impartida por Max Uhle el 19 junio 1914 en Santiago de Chile ${ }^{4}$}

[1] Las condiciones geográficas de Chile son únicas tanto respecto a su delimitación política como respecto a las condiciones para la vida del hombre. El país se extiende como una faja larga pero angosta por tres climates [sic] estrechada por el mar en uno de 
sus lados, por una cordillera casi intransitable por otro. Sus condiciones para vivir no son extraordinariamente favorables. El norte con su clima caliente ofrece fuera de desiertos inmensos pocos valles aptos para la agricultura, el centro con sus valles angostos entre cerros y serranías y con su clima menos blando no recompensa los trabajos del hombre como la tierra de los trópicos, y en las regiones frías del sur el hombre apenas es capaz de llevar una existencia muy indigente por la escasez de los recursos ofrecidos por la naturaleza.

La cordillera al este forma una valla que parece separar al habitante del país del mundo entero. Servía al hombre primitivo como una defensa contra las irrupciones continuas de las hordas generalmente turbulentas del este. Naciones se podían consolidar por eso en el recinto del país, ganar fuerza y entrar en un camino de desarrollo que necesariamente las tenía que llevar al fin a la civilización. Por el otro lado, existía el peligro de la estagnación por la falta de contacto continuo con naciones vecinas.

Como el clima, también las condiciones de civilización eran diferentes entre los vecinos del norte y sur. De los vecinos salvajes del sur no se podía sacar ningún beneficio para el adelanto de la civilización en el mismo territorio. Felizmente se desarrollaron civilizaciones muy adelantadas entre los vecinos del norte, que por su empuje al sur tenían por necesidad que llevar los primeros elementos de civilización a las [2] naciones de Chile, y así esas recibieron lo que les era más menester, ideas de progreso que los podían encaminar en un desarrollo de civilización no estorbado por las hordas intranquilas del este.

La historia antigua de Chile es una de sus razas originales y una de sus civilizaciones antiguas. Las razas daban el fundamento de las naciones que se formaron, pero no eran enteramente idénticas con la extensión de los tipos de las civilizaciones. Mucho menos variedad se encuentra en el tipo de las naciones que entre los tipos antropológicos que desde tiempo muy antiguo se encuentran en el suelo chileno.

Según Latcham [1912], quien los ha estudiado más cuidadosamente que nadie, los habitantes antiguos de Chile en todas sus partes están lejos de presentar un tipo antropológico homogéneo. En todas partes se encuentra una enorme mezcla de tipos originalmente muy diferentes, que evidencian la composición de las poblaciones por elementos muy diferentes, que sucesivamente entraron del este.

[3] [Varias líneas tachadas] Hay cabezas largas y cortas y de todas otras formas posibles, con narices delgadas y largas, $\mathrm{o}$ anchas y cortas, narices derechas o cóncavas, numerosos casos de la grosura de los cráneos, y de techos de cráneos en forma de cresta significados con el nombre de escafocefalia, que dan indicios de la antigüedad y primitividad de los tipos. Aunque estas anomalías aparecen en un número más grande entre los cráneos antiguos de Chile que en colecciones formadas en otras partes, en aquellas otras regiones, como en Perú, no faltan tampoco, y solo menos se observan por ser algo menos frecuentes.

En la distribución de los diferentes tipos de cráneos conocidos, se observa que los tipos de cráneos largos más se encuentran en regiones periféricas y menos accesibles, como en algunas partes de la costa y en la cordillera interior, [y] los de los cráneos cortos parecen más frecuentes en partes centrales, como por ejemplo del valle longitudinal.

[4] Cráneos largos se han observado por ejemplo en toda la costa de Arauco a Imperial, en la isla de Mocha, entre los Mapuches sub-andinos y entre los Pehuenches de la Cordillera; cabezas cortas, por ejemplo en la región interior entre los ríos Biobío e Itata, cerca del río Rapel, pero también muy al sur, en la isla de Chiloé.

En las poblaciones antiguas se pueden distinguir algunos grupos antropológicos de más importancia. Uno de los tipos más principales son [los] Araucanos, oscuros de cabeza grande y alta pero corta, con nariz ancha, tronco grande y ancho, pecho bien desarrollado, y extremidades cortas y gruesas, que se encuentran especialmente en el sur, [y] también en Chiloé. La relación de este tipo con otros que dominan en una gran parte del este Argentino no se puede desconocer. Otro tipo de observación menos fácil se presenta, según Latcham, en poblaciones de color bien oscuro, bien pelosos, con cabeza chica, nariz cóncava, frente ancha y alta, tronco corto, pero extremidades delgadas.

[5] Observo la existencia de otro tipo más, en el norte, de color algunas veces bastante oscuro, cabeza corta, cara algo prognata pero delgada, con maxilares no salientes y nariz derecha, algunas veces aguileña. La figura generalmente delicada, es caracterizada por el pelo algo ondulado, parecido al que se encuentra frecuentemente entre las naciones de la hoya del Amazonas. Este tipo se deja observar desde Copiapó hasta la región del Rapel en el Sur, pareciendo característico a las poblaciones diaguitas que habitaron el norte, porque de forma idéntica se repite como el tipo común en los valles calchaquí y de Catamarca en el lado argentino.

El tipo atacameño no está bien determinado todavía. Se encuentra en cráneos de los cementerios atacameños antiguos y parece mezclado, prevaleciendo los cráneos cortos. Es un tipo independiente de los tipos bolivianos vecinos del norte, porque los Chichas en el sur de Bolivia ostentan marcadas diferencias de todos los otros tipos conocidos de esas regiones andinas.

Dos tipos de la región costeña merecen una atención especial. El de una población suma[6]mente antigua, encontrada por Latcham [1910], en conchales sumamente antiguos a poca distancia de Coquimbo. Su cráneo con una cara chata y forma elipsoide horizontal parece presentar 
estrechas semejanzas con cráneos Yahganes y otros tipos primitivos del este de Brasil. Cráneos parecidos de la región de Valdivia en el Sur se distinguen de los de Coquimbo por su nariz algo más ancha.

El segundo tipo original y diferente de los otros encontrados en el suelo chileno, en el norte, es el de los Changos casi extinguidos ahora. Su cabeza generalmente cuadrada con cara un poco prognata es especialmente caracterizada por su nariz cóncava, ancha y corta, como casi no se conoce de algún otro tipo americano. Eso prueba la dificultad de mantener la extensión de una raza andina en la forma determinada por d'Orbigny, quien incluyó a los Changos con los Kechuas y Aimaras en una misma familia.

Todos los individuos de la familia chilena tienen generalmente una talla poco alta, alcanzando algunas veces apenas la mediana de 160 centímetros. También la raza de los Changos cuenta entre las razas chicas, porque sus individuos apenas alcanzan una altura de 158 centímetros.

[7] Por los trabajos de Medina [1882], Guevara [18981913] y Lenz [1895-1897] se han ensanchado nuestros conocimientos sobre los tipos de las civilizaciones y lenguas antiguas, que facilitan extensamente la reconstrucción de la historia de las civilizaciones.

Los restos de las poblaciones más primitivas del país se pueden observar en la costa, en los conchales y paraderos antiguos, mientras los restos de los habitantes contemporáneos del interior raramente se encuentran.

Los restos más antiguos de la costa parecen presentar el nivel de la civilización que acompañaba al indio en su inmigración en el continente. Porque representando ellos formas de vivir sumamente primitivas, no se puede creer que el indio al inmigrar haya poseído un tipo de mayor civilización que el más bajo que se encuentra en algunas partes del continente. De esa manera las condiciones de los habitantes muy primitivos del país ofrecen un material valioso para la determinación de la base original de las civilizaciones americanas. Los restos del hombre primitivo de la costa son de diferente edad. Los más antiguos conocidos son los de las extensas capas de ceniza, a una legua de Coquimbo, de las cuales Latcham reconstruyó su tipo paleo-americano. Datan de una época muy remota, de un periodo en que las condiciones del litoral y la extensión del mar en la costa presentaban un aspecto todavía muy diferente del de ahora. En aquellos paraderos, antes todavía más [8] inmediatos al mar, el hombre primitivo vivía con el conocimiento del fuego y con algunos instrumentos de hueso, de los productos del mar, cazando lobos marinos, pescados, aves, y buscando mariscos. Era también antropófago, y enterraba a sus muertos echados y con [las] piernas irregularmente dobladas.

Otros restos de gran antigüedad encontrados en la ínfima capa dentro de una cueva cerca de Pisagua, parecen evidenciar que el hombre más primitivo de aquellos parajes vivía del viru [sic] del mar, tapándose con tejidos pequeños hechos de las fibras de totora que recogió en los ríos de la costa vecina.

Las formas primitivas de vivir tenían en la costa una diferente duración según el carácter de las poblaciones y las distancias del área de civilizaciones superiores.

$\mathrm{Al}$ principio de nuestra era el hombre de Pisagua vivía todavía sin el conocimiento de la alfarería, pescando con flechas con el uso de la estólica y tapándose con pedazos de tejidos gruesos de lana, recibidos a trueque de poblaciones más adelantadas del interior. Sus habitaciones solo pueden haberse formado de totora y pieles no dejando vestigios.

Muchos siglos después, habitantes primitivos de la costa de Constitución en el Sur vivían todavía como el hombre primitivo cuaternario de Europa, con instrumentos de piedra sumamente sencillos, y los Changos de Caldera al norte habían conservado su forma primitiva de vivir como nómades de agua casi sin abrigo alguno, casi sin el uso de alfarería, [9] y aprovechando generalmente de agua algo salada hasta muy pocos decenios atrás del tiempo presente.

Ni [las] hordas más primitivas del este de la cordillera tenían que envidiar a esos nómades del mar por sus condiciones de vivir tan primitivas. Por el otro lado, hay relaciones curiosas [de civilización] entre los habitantes de estas costas del norte y los Yahganes en la Tierra del Fuego. Las muchas clases de instrumentos de pesca y de otra clase. De unos y otras usaban las mismas clases de adornos hechos de fragmentos de huesos, y todos usaban canastas de cargar de una identidad formal sorprendente, eran enteramente parecidos.

Poblaciones deeste tipoantropológicoy de civilización habrán ocupado todo el país hasta la inmigración de elementos de menos rudeza, y más disposición para el desarrollo de civilizaciones.

En el Sur entraron grupos del noreste con un tipo de civilización probablemente parecido a los Ges del este del Brasil. Los Araucanos tenían la costumbre de enterrar en canoas o troncos de arboles, o de enterrar los restos desechos por segunda vez en ollas de greda, como muchas tribus del interior de Brasil. Su palabra "co", que significa "agua", es idéntica con la de las lenguas Ges, y la comparación de algunas de las palabras más importantes de su lengua, como de las por "fuego", "luna", "ojo", "mano", con otras de la misma significación en las lenguas de los Ges prometen descubrimientos de interés sobre su origen noreste. El pronombre de la primera persona $i \tilde{n}$, muestra apenas alguna diferencia del usado en algunos dialectos de los Guaycurús del Chaco argentino, y en algunas lenguas de los Ges en el este del Brasil.

Con esos inmigrantes llegó al país un elemento fuerte y robusto y de costumbres sanas, que separado [10] de las turbulencias de las naciones del este, 
bien pudo formar una base para un desarrollo de la civilización del país.

Por lo primero, eran cazadores y pescadores sin paradero muy fijo, usaban como armas porras de madera, arcos y flechas, como vestimenta pieles para adorno, plumas, y consultaban a curanderos para cuestiones de medicina $o$ de religión, como las naciones del este. Tales condiciones parecen haberse encontrado en un periodo relativamente moderno en la región entre los ríos Itata y Toltén.

Más al norte, entraron poblaciones diferentes descendientes de los Diaguitas del este. La identidad de su carácter con los de sus vecinos del otro lado de la cordillera se manifiesta como en su tipo antropológico, en la forma de su civilización, el carácter de su alfarería, sus maneras de enterrar, y sus pueblos construidos en la vecindad de la cordillera.

Parece que los Araucanos del Sur y los Diaguitas del Norte se penetraron mutuamente en una región limítrofe. Porque mientras la extensión del tipo antropológico de las poblaciones del norte alcanza al río Rapel, poblaciones de Picones o Picunches, Diaguitas se encontraron, según las observaciones de Joaquín Santa Cruz en Melipilla cerca del río Maipo, y cementerios con los tipos de la alfarería pintada del norte se encuentran en el sur hasta el río Maipo; el araucano parece haberse hablado en el tiempo del descubrimiento hasta la región de Copiapó, nombres geográficos [11] de origen araucano, muy numerosos hasta Illapel, alcanzan a la región de Coquimbo, y las piedras de tacitas de origen araucano distribuidas sin interrupción en el país hasta el grado 42 de latitud, según Guevara, tienen sus últimos representantes al norte en la región de Ovalle.

Los Atacameños de los oasis del desierto de Atacama parecen otra tribu de afinidades orientales. Su origen del este se documenta no solo en el carácter prefijador [de la lengua], como todas las otras lenguas del este, sino también en la semejanza de su pronombre de la primera persona, con el de varias tribus como de los Machicuy y otros parecidos del estado de Matto Grosso en el Brasil. Como todas las otras naciones del este, usaban el arco de forma corta, y por su uso palas de madera o piedra como sus instrumentos de agricultura se encuentran en compañía con los Chichas del valle de Ica en el Perú, los Chichas del Sur de Bolivia, los Chiriguanos y poblaciones antiguas de la sierra de Córdoba en la Argentina.

Del origen y de las costumbres de sus vecinos del norte, los Chichas, tenemos poco conocimiento. Para Chile son de importancia por los nombres geográficos derivados de su lengua desconocida, que se extienden por todo el sur y el oeste de Bolivia al sur y por la provincia de Tarapacá quizá hasta Moquegua en el norte.

Más al norte se encontraban los Uros. Inmigrantes del este, porque su lengua tiene muchas semejanzas con las lenguas del este de Bolivia y también del Brasil, se extendieron, quizá en tiempo muy remoto, hasta la costa del Pacífico entre Cobija y Arica. Muchos nombres geográficos en las faldas [12] de la Cordillera por el lado Pacífico se explican por medio de su lengua.

Sin la entrada de las civilizaciones peruanas del norte, todas esas naciones habrían permanecido quizá en el estado de salvajismo original característico para las naciones del este. Pero con esa se produjo aquella transformación que llevó la mayor parte de las naciones chilenas del norte al sur hasta el límite de una civilización adelantada.

Las influencias de todas las civilizaciones principales del antiguo Perú se han dejado sentir en el suelo chileno, y, con excepción de la primera de Proto Nazca cuyos efectos no se pueden determinar todavía al sur del desierto de Atacama, han alcanzado por todo el país hasta Valdivia y Chiloé en el sur.

Los efectos de la civilización de Proto Nazca, que florecía en los primeros siglos de nuestra era, son muy perceptibles en el más antiguo de los cementerios estudiados cerca de Pisagua en el año pasado.

En lugar de un número escaso de individuos que vivía de algas del mar y se vestía con tejidos pequeños de totora como en el periodo anterior, encontramos en ese cementerio numerosas sepulturas con un extenso aparato de estólicas, flechas, harpones [sic], y puntas de flecha de piedra para pescar, numerosas canastas grandes bien trabajadas y adornadas, adornos de hilos, y varios objetos de hueso y otro material. Los cadáveres se enterraban más o menos en la posición en que los había dejado la vida. No se conocía todavía el uso de los vasos de greda, ni el del perro domesticado. [13] Se encuentran pedazos de tejido de lana gruesa y tosca, pero generalmente de color natural, y faltando instrumentos de hilar y tejer, parece seguro que esos tejidos e hilos de lana se habían conseguido a trueque. La forma del poncho como objeto de vestido parece haber estado desconocida todavía. Pero se han encontrado algunos gorros tejidos a punto. Sus hermosos dibujos y los de las canastas ponen de manifiesto su contemporaneidad con la civilización peruana de Proto Nazca, y los efectos de las influencias recibidas directamente o indirectamente de su lado.

Tejidos de grosura y primitividad igual, y gorros de lana tejidos a punto se encuentran también en los cementerios atacameños del sur que parecen contener restos mezclados de diferentes periodos. Por eso es probable que influencias del mismo periodo de civilización peruana llegaron hasta los oasis de Atacama, como pasaron a las provincias argentinas según la ornamentación de algunos vasos encontrados en aquellas regiones.

Las influencias del periodo de Tiahuanaco marcan la edad del segundo cementerio encontrado cerca de Pisagua. En ese ya aparecen vasos toscos de greda, el poncho de tejido regular de lana, y algunos instrumentos para hilar hacen su primera entrada. El uso de la estólica 
se ha remplazado por el del arco y ya hay numerosas momias de perros en el mismo cementerio. Principia un modo más ordenado de enterrar, y aparecen las primeras momias vestidas con piernas bien dobladas aunque en posición siempre echada. Aparecen tejidos con reproducciones de las figuras de la puerta monolítica de Tiahuanaco, y los bordados encima de las costuras de los ponchos dan las figuras de cabezas de cóndores y otras características de la ornamentación tiahuanaqueña.

[14] Ese cementerio de pobres pescadores de Pisagua fue por eso contemporáneo como con las ruinas de Tiahuanaco, también con las hermosas alfarerías y los objetos sacados de los cementerios de Tacna y Arica del mismo periodo.

A las influencias de la civilización de Tiahuanaco se debe en todo el sur la introducción del arte de tejer y teñir, y la domesticación del llama. Con la introducción de la civilización de Tiahuanaco de sus industrias, y del usa del llama como animal doméstico, se deben en los oasis de Atacama los primeros vestigios de la población allá existente. Porque solo desde ese periodo se encuentran allá cementerios extensos con restos de numerosos individuos. Las influencias de la civilización de Tiahuanaco son allá muy visibles en el conocimiento del arte de tejer, en el uso de numerosos colores para teñir, en los principios del arte de fundir el cobre y tabletas y tubos de madera, que reproducen las formas de instrumentos y figuras de ornamentación conocidas de las ruinas de Tiahuanaco.

Sobre la forma de las influencias directas de ese periodo en la región entre el desierto de Atacama y el valle del Aconcagua nada se conoce todavía.

Las excavaciones del Doctor Fonk [1910] cerca de algunas piedras de tacitas en los alrededores de Quilpué han traído a la luz, entre otros, vasos de greda, uno pintado con figuras de un ornamento textil muy común en tejidos y vasos del periodo de Tiahuanaco en el Perú. Este único resto basta para determinar todos los otros hallazgos de ese sitio como originarios del mismo periodo. Son, fuera de las piedras de tacitas mismas en cuya proximidad se encontraron los otros restos, hachas de piedra bien pulidas, puntas de flecha [15] muy bien labradas, piedras horadadas y otros objetos semejantes más. Según eso, se pueden determinar las piedras de tacitas de todo Chile como originarias del tiempo de Tiahuanaco, con una edad de más o menos 1200 años antes de ahora. En aquel tiempo las poblaciones araucanas tuvieron por eso una extensión hasta Ovalle en el norte, donde se encuentra la primera de esas piedras andando al sur.

El uso de puntas de flecha y de hachas de piedra bien labradas en el territorio del sur se pueden considerar según eso como otros efectos de las influencias de la civilización de Tiahuanaco en el Sur. La edad de la piedra pulida parece por eso haber principiado en el sur con la introducción de esa civilización maravillosa del norte.
La arqueología de la región al sur de esta capital no se ha estudiado todavía. Pero ya se pueden discernir algunas líneas fundamentales del desarrollo cronológico que ha habido en el sur.

Ya se ha hecho mención anteriormente del vaso de piedra sacado del fondo del lago Tagua Tagua, cuya forma y ornamentación indican infaliblemente su origen bajo las influencias de la civilización de Tiahuanaco. Estas alcanzaron por eso a aquellas regiones del sur. La resistencia de un pueblo unido que encontraron los Incas en su invasión del territorio al sur del río Maule, evidencia que los Incas ya tenían que hacer con un pueblo semi civilizado bastante numeroso, bien organizado y sin duda ya sedentario. El llama era el animal doméstico hasta Chiloé ya en el tiempo de la invasión de los Incas. Se conocía el arte de tejer hasta Chiloé y se formaban tejidos adornados con listones en diferentes colores. [16] Una agricultura ordenada estaba en uso en la isla de Chiloé ya al tiempo de la invasión de los Incas en Chile, y la producción de la papa, hasta hoy el producto principal de la agricultura de Chiloé, se debe haber aprendido de la civilización de Tiahuanaco pero no de los Incas, que habrían introducido simultáneamente también otras clases de agricultura.

No es probable que el carácter subfijador del idioma araucano sea un carácter original de la lengua. Porque los varios elementos de la población llegaron del este, donde no se conocieron lenguas de ese tipo adelantado. El tipo subfijador en las lenguas andinas de Sudamérica parece un elemento de civilización como cualquier otro que esas propagaron en su adelanto al sur. Además el carácter subfijador de la lengua araucana parece de origen más nuevo que el de las lenguas del antiguo Perú como el Kechua y Aimara. Porque en el araucano se subfijan elementos que están todavía en uso como pronombres independientes, y no elementos ininteligibles y en parte fosilizados como en aquellas lenguas peruanas más antiguas. Pero cuando los Incas invadieron el país, el tipo de la lengua presente estaba evidentemente formado, y como la palabra araucana pataka por cien se ha derivado del aimara y no del kechua, toda la lengua habrá adquirido su tipo subfijador por las influencias de la civilización aimará de Tiahuanaco. [17] Se puede decir por eso que el pueblo y el último tipo de la civilización araucana estaban ya completamente organizados al tiempo de la invasión de los Incas, y se habrán formado por eso al menos un milenio antes del tiempo presente.

Al periodo de Tiahuanaco sucedió en el norte de Chile otro especial de carácter atacameño. Influenciados por la civilización de Tiahuanaco, los atacameños formaron un tipo especial de civilización propia caracterizado por el uso de muchos objetos, vasos, tabletas, tubos, y cucharitas, de madera, vasos y cucharitas de hueso, bolsas tejidas con ornamentación de listones, cascos de guerra formados de palitos, y algunos otros objetos de un tipo propio más. 
Este tipo de civilización tiene para el norte de Chile el valor de un periodo especial, porque se han encontrado en varias partes, como en Caldera, Pisagua y otros lugares, cementerios enteros caracterizados cronológicamente por ese tipo especial. Varios cementerios más como uno en Llolleo cerca de San Antonio, estudiado por el Doctor Oyarzún [1909], [y] otros cerca de Coquimbo, se pueden atribuir por el tipo de su alfarería, en mucho respecto parecido a la atacameña, al mismo periodo.

Entre Copiapó y el río Maipú se extendió otra forma de civilización derivada de la de Tiahuanaco, la de la civilización diaguita. Sus tipos de alfarería pintada son los más hermosos encontrados en el suelo chileno. Los varios dibujos de los vasos nos cuentan de una industria de tejidos ricamente ornamentada, cuyos productos no encontrados todavía deben existir en el suelo del norte.

[18] Había una industria bien desarrollada de objetos de cobre producidos en formas variadas. Esos y los productos ricos de alfarería se negociaban en el norte hasta más allá de Caldera y los oasis del desierto de Atacama.

Tal era la condición del país cuando los Incas hicieron su entrada en él por el norte.

El Inca Garcilaso [1609] nos ha transmitido una descripción vívida de la forma en que los Incas procedieron en sus conquistas del sur.

Según esa, el territorio atacameño ya estaba incorporado en el imperio del norte, cuando Inca Yupanqui resolvió la conquista de las provincias vecinas del sur. Las fortalezas incaicas en la región de Chiuchiu no pueden haberse construido por eso en un tiempo posterior al principio del siglo quince, porque formaron la base para las operaciones del Inca más al Sur. Con mucho cuidado se exploraron por medio de espías las comunicaciones a través el desierto de Atacama en dirección a Copiapó, y una vez hecho eso, un ejército incaico numeroso atravesó el desierto sorprendiendo y conquistando a la provincia de Copiapó. Varios ejércitos sucedieron uno al otro probablemente para regresar nunca y para quedar como colonos en las provincias anexadas. Los ejércitos incaicos llegaron sin grandes dificultades hasta el valle longitudinal y la orilla del Maule, porque tenían que hacer en todo ese trayecto solo con poblaciones mezcladas con elementos diaguitas. Pero pasando el río Maule y entrando en el territorio mapuche propio, encontraron una resistencia tan resuelta por parte de los indígenas reunidos de toda la provincia para el combate, que, como Garcilaso se expresa, les pareció a los Incas más conforme dar lugar al bestial furor de los enemigos que destruirlos [19] para sujetarlos, y así señalaron el Río Maule por término de su imperio, para atender con mucho cuidado en cultivar y beneficiar lo que habían ganado. La realidad de los hechos y las obras iniciadas por los Incas en las nuevas provincias corresponden a esa descripción dada por Garcilaso.

En diferentes lugares han quedado nombres geográficos de origen kechua, como cerca de Santiago: Apoquindo, Pachacama en el valle de Aconcagua, numerosos en la región de Coquimbo y Copiapó, como el de Copiapó mismo, todos los compuestos con lume, que es una transformación dialéctica del kechua rumi, piedra, etc.

Los acequias antiguas en los alrededores de Santiago y cerca de Talagante son obras dejadas por la ocupación incaica. En muchas otras partes, como hasta el río Maule, había o hay restos de fortificaciones incaicas instaladas en cerros, con que aseguraban la sumisión de sus nuevos súbditos. En otras partes, los Incas trabajaban en minas.

No creo que toda la civilización encontrada por los españoles en la región de Santiago fuera obra de los Incas, porque la presencia de vasos preincaicos bien pintados con ornamentaciones de diferente clase en algunos cementerios hasta la región del Maipú, hace probable que los que los fabricaron conocieron también el uso de tejidos ornamentados con iguales dibujos. Pero quedan numerosos objetos en la civilización araucana postincaica, cuyo origen no puede haber sido otro que por su adopción de los Incas.

Las diferentes clases de productos de agricultura de la región se habrán multiplicado en ese periodo. $\mathrm{La}$ comida se habrá civilizado. Diferentes platos ahora comunes, como locro, mote, indican ya por su nombre su introducción por los Incas. Como panes hechos de maíz, se encuentran en el Perú solo en entierros del último tiempo prehispano, [20] la costumbre de su confección habrá llegado a la región araucana solo en el tiempo de los Incas. Igual cosa se puede quizá decir del uso de los quipus adoptado por los araucanos, porque como esos aparatos de contaduría faltaban en entierros antiguos del Perú anteriores al periodo de los Incas, también su uso por los araucanos con diferenciación del color de los hilos para fines de contaduría más especializada, se habrá debido a las enseñanzas de los Incas.

Varios instrumentos de música poseen nombres quechuas, los que prueban su introducción por los incas. Y varios nombres quechua que se refieren a artículos de vestir, como poncho, lliclla, wincha, topo, han entrado también en el uso araucano, con que se manifiesta la introducción de nuevas ideas y formas en su indumentaria.

Las influencias de la civilización de los Incas llegaron a partes del Sur aún no conquistadas. Pruebas de esas son las alfarerías de ornamentación incaica hechas y encontradas en la región de Valdivia. Con eso se explica la introducción de nuevas industrias en el arte araucano que sin esa derivación de la civilización de los Incas serían de todo ininteligibles. 
En un entierro cerca de Osorno se ha encontrado el fragmento de un pinche de plata de forma incaica. Parece hasta ahora el único objeto de metal encontrado en uno de los entierros prehispanos. Más nueva es por eso toda la industria araucana de objetos de plata ahora tan desarrollada. Sus modelos tienen por lo general un carácter original o hispano, pero se encuentran entre esas orejeras de plata idénticas por su forma [21] a otros que comúnmente se encuentran en entierros del periodo incaico en el valle de Lima.

Igual cosa se puede decir de la ornamentación usada en tejidos araucanos modernos. Una parte de esa ornamentación se puede haber derivado de la ornamentación usada antiguamente entre los Diaguitas. Porque por ejemplo las figuras de cruces ahora tan comunes en tejidos araucanos modernos se encuentran ya frecuentemente en la ornamentación de la alfarería diaguita antigua del norte. Otros dibujos en forma de gradas muy comunes en las caronas araucanas tejidas representan un dibujo tan característico e individual, que su repetición en tejidos en entierros incaicos del Perú nos enseña inmediatamente de donde los araucanos lo sacaron.

Con mucha inteligencia los araucanos adoptaron para su uso detalles vistos en objetos de la civilización de los Incas, aunque esa nunca llegó, mismo [por] conquistas militares hasta el último sur, y esa observación a mi parecer vale más que vindicar a su propia invención progresos que no podrían haber hecho por sí mismos, y tarde o temprano aparecerían como debidas a enseñanzas forasteras.
Todo eso prueba que a la nación araucana nunca faltaba una buena porción de inteligencia natural, solo le faltaron por un número de siglos los maestros que la condujeran a la civilización.

Concluyendo con eso mi curso de conferencias, deseo dejar constancia que el número de problemas de etnología sudamericana que quedan para resolver es muy superior al de los resueltos en la corta historia de unos cincuenta [22] años del desarrollo de la ciencia americana. Al mismo tiempo deseo que quede establecido que cualquier solución dada a algún problema de etnología sudamericana representará al mismo tiempo una contribución valiosa a los problemas de historia antigua, que nos ocupan preferentemente en Chile, como por el otro lado una solución completa de los problemas de la historia antigua de Chile significará al mismo tiempo e infaliblemente que se han resuelto definitivamente todos los problemas que atañen a la etnología sudamericana.

Agradecimientos: La investigación que llevó a este documento fue posible por una beca de residencia en el Institut d'études avancées (IEA) de Paris, en el marco del programa estatal francés "Investissements d'avenir" de la Agence Nationale de la Recherche (ANR -11-LABX-0027-01 Labex RFIEA). También agradezco a Gudrun Schumacher y el equipo del Instituto Iberoamericano (IAI) de Berlín por facilitar la reproducción del documento, y a los evaluadores de Chungara por sus importantes sugerencias.

\section{Referencias Citadas}

Allison, M.J., G. Focacci, B. Arriaza, V. Standen, M. Rivera y J. Lowenstein 1984. Chinchorro, momias de preparación complicada: Métodos de momificación. Chungara Revista de Antropología Chilena 13:155-173.

Álvarez, L. 1974. Homenaje a Max Uhle. Antecedentes sobre su primera comunicación pública de Los aborígenes de Arica. Chungara Revista de Antropología Chilena 3:9-11.

Arriaza, B. 1995. Chinchorro bioarchaeology: Chronology and mummy seriation. Latin American Antiquity 6 (1):35-55.

Arriaza, B. 2005. Cultura Chinchorro. Las Momias Artificiales más Antiguas del Mundo. Editorial Universitaria, Santiago.

Canales, P. 1910. Los cementerios indígenas en la costa del Pacífico. Actas del XVII Congreso Internacional de Americanistas, pp. 273-297. Sociedad de Americanistas, Buenos Aires.

Dauelsberg, P. 1995. Dr. Max Uhle: su permanencia en Chile, de 1912 a 1919. Beiträge zur allgemeinen und vergleichenden Archäologie 15:371-394.

Delegación Chilena 1910. El Congreso de los Americanistas en Buenos Aires. Mayo de 1910 (Datos recopilados por la Delegación Chilena). Anales de la Universidad de Chile 127:633-735 y 879-904.
Erhardt, H. 1998. Max Uhle en Chile (1912-1919). Sus aportes pioneros al estudio del Precerámico costeño. Indiana 15:107-138.

Gänger, S. 2011. The Collecting and Study of Pre-Hispanic Remains in Peru and Chile, c. 1830s-1910s. PhD. Dissertation in History, University of Cambridge, Cambridge.

González Pizarro, J.A. 2014. Ricardo E. Latcham, un científico social. Desde las observaciones etnográficas de la sociedad hasta la arqueología de las culturas originarias chilenas. Alpha (Osorno) 38:67-88.

Guevara, T. 1898-1913. Historia de la Civilización de la Araucanía, siete volúmenes, Imprenta Barcelona e Imprenta Cervantes, Santiago.

Guevara, T. 1925. Historia de Chile: Chile Prehispano. Tomo 1. Imprenta Balcells, Santiago.

Gusinde, M. 1916. El Museo de Etnología y Antropología de Chile. Publicaciones del Museo de Etnología y Antropología 1 (1):1-18.

Latcham, R.E. 1910. Los Changos de las Costas de Chile. Imprenta Cervantes, Santiago.

Latcham, R.E. 1912. Los elementos indígenas de la raza chilena. Revista Chilena de Historia y Geografía 8:303-329. 
Latcham, R.E. 1925. La Organización Social y las Creencias Religiosas de los Antiguos Araucanos. Imprenta Cervantes, Santiago.

Latcham, R.E. 1938. Arqueología de la Región Atacameña. Universidad de Chile, Santiago.

Lehmann-Nitsche, R. (ed.) 1912. Actas del XVII Congreso Internacional de Americanistas, Buenos Aires, 17 al 23 de mayo de 1910. Imprenta de Coni Hermanos, Buenos Aires.

Llagostera, A. 2003. Patrones de momificación Chinchorro en las Colecciones Uhle y Nielsen. Chungara Revista de Antropología Chilena 35 (1):5-22.

Mc Evoy, C. 2011. Guerreros Civilizadores. Política, Sociedad y Cultura en Chile durante la Guerra del Pacífico. Ediciones UDP, Santiago.

Mora Nawrath, H. 2016. Dinámicas de campo en la emergencia de la antropología científica en Chile. CUHSO. CulturaHombre-Sociedad 26 (2):107-145.

Mostny, G. (ed.) 1964. Arqueología de Taltal. Epistolario de Augusto Capdeville con Max Uhle y otros Arqueólogos e Historiadores. Compilación, introducción y notas de G. Mostny, 2 tomos, Fondo Histórico y Bibliográfico José T. Medina, Santiago.

Nastri, J. 2010. Max Uhle y la prehistoria del noroeste argentino. En Max Uhle (1856-1944). Evaluaciones de sus Investigaciones y Obras, editado por P. Kaulicke, M. Fischer, P. Masson y G. Wolff, pp. 25-48. Pontificia Universidad Católica del Perú, Lima.

Nuñez, L. 2010. Las investigaciones de Friedrich Max Uhle en el desierto de Atacama (norte de Chile). En Max Uhle (18561944). Evaluaciones de sus Investigaciones y Obras, editado por P. Kaulicke, M. Fischer, P. Masson y G. Wolff, pp. $337-$ 348. Pontificia Universidad Católica del Perú, Lima.

Orellana, M. 1996. Historia de la Arqueología en Chile. Bravo y Allende editores, Santiago.

Oyarzún, A. 1979. Contribución al estudio de la influencia de la civilización peruana sobre los aborígenes de Chile. En Estudios Antropológicos y Arqueológicos, editado por M. Orellana, pp. 27-44. Editorial Universitaria, Santiago.

Parentini, L.C. 1996. Introducción a la Etnohistoria Mapuche. Dirección de Bibliotecas, Archivos y Museos, Santiago.

Pavez, J. 2015. Laboratorios Etnográficos. Los Archivos de la Antropología en Chile (1880-1980). Ediciones de la Universidad Alberto Hurtado, Santiago.

Penny, G. 2003. Bastian's Museum: On the limits of empiricism and the transformation of German ethnology. En Wordly Provincialism. German Anthropology in the Age of Empire, editado por H.G. Penny y M. Bunzl, pp. 86-126. The University of Michigan Press, Ann Arbor.

Rivera, M. 1995. The Preceramic Chinchorro Mummy Complex of Northern Chile: Context, style, and purpose. En Tombs for the Living. Andean Mortuary Practices, editado por T.D. Dillehay, pp. 43-77. Dumbarton Oaks Research Library and Collection, Washington, DC.
Rowe, J. 1954. Max Uhle, 1856-1944. A Memoir of the Father of Peruvian Archaeology. University of California Press, Berkeley.

Rowe, J. 1998. Max Uhle y la idea del tiempo en la arqueología americana. En Max Uhle y el Perú Antiguo, editado por P. Kaulicke, pp. 5-21. Pontificia Universidad Católica del Perú, Lima.

Santoro, C., V. Standen, B. Arriaza y F. Rothhammer 2010. El legado de Max Uhle en la arqueología de Arica. En Max Uhle (1856-1944). Evaluaciones de sus Investigaciones y Obras, editado por P. Kaulicke, M. Fischer, P. Masson y G. Wolff, pp. 349-357. Pontificia Universidad Católica del Perú, Lima.

Tylor, E.B. 2012 [1871]. Primitive Culture. Cambridge University Press, Cambridge.

Uhle, M. 1912. Tejidos Protonascas (resumen). Revista Chilena de Historia y Geografía 8:553-554.

Uhle, M. 1913. Tiahuanaco e Inca (resumen). Revista Chilena de Historia y Geografía 10:496.

Uhle, M. 1914. La estación paleolítica de Constitución (resumen). Revista Chilena de Historia y Geografía 14:494-495.

Uhle, M. 1915a. Investigaciones arqueológicas en Constitución (resumen). Revista Chilena de Historia y Geografía 18:493.

Uhle, M. 1915b. Las piedras de tacitas (resumen). Revista Chilena de Historia y Geografía 18:493.

Uhle, M. 1915c. Quivolco-Vortrag. Conferencia en la Sociedad Chilena de Historia y Geografía, 1 mayo 1915: "Investigaciones Arqueológicas en Constitución”, Legajo Max Uhle, carpeta 43, Instituto Iberoamericano, Berlín.

Uhle, M. 1919. La arqueología de Arica y Tacna. Boletín de la Sociedad Ecuatoriana de Estudios Históricos Americanos 3 (7-8):1-48.

Uhle, M. 1922. Fundamentos Étnicos y Arqueología de Arica y Tacna. Sociedad Ecuatoriana de Estudios Históricos, Quito.

\section{Referencias citadas en la transcripción}

Fonck, F. 1910. La Región Prehistórica de Quilpué y su Relación con la de Tiahuanacu. Soc. Imprenta y Litografía Universo, Valparaíso.

Guevara, T. 1898-1913. Historia de la Civilización de la Araucanía 7 volúmenes, Imprenta Barcelona e Imprenta Cervantes, Santiago.

Latcham, R.E. 1910. Los Changos de las Costas de Chile. Imprenta Cervantes, Santiago.

Latcham, R.E. 1912. Los elementos indígenas de la raza chilena. Revista Chilena de Historia y Geografía 8:303-329.

Lenz, R. 1895-1897. Estudios Araucanos, Imprenta Cervantes, Santiago.

Medina, J.T. 1882. Los Aboríjenes de Chile. Imprenta Gutenberg, Santiago.

Oyarzún, A. 1909. Los Kjoekkenmoedinger o Conchales de la Costa de Melipilla i Casablanca. Soc. Imprenta y Litografía Universo, Santiago. 


\section{Notas}

${ }^{1}$ Aunque también regala e intercambia algunas piezas de esta campaña con otros museos, como la colección que envía para el Museo Paulista de von Ihering en 1912 (cf. Rowe 1954:13), entre ella una "momia de Chiu Chiu" luego exhibida en el Museo Nacional de Río de Janeiro, hasta que este fue completamente destruido por el trágico incendio de 2018.

${ }^{2}$ Cinco conferencias se encuentran resumidas en la Revista de la Sociedad Chilena de Historia y Geografía, y sus manuscritos completos disponibles en el Fondo Uhle del IAI en Berlin. Se trata de la conferencia del 28 de septiembre 1912, "Tejidos protonascas”(Uhle 1912); “Tiahuanaco e Inca” (Uhle 1913); del 28 marzo 1914 "La estación paleolítica de Constitución (Uhle 1914); del 1 mayo 1915 "Investigaciones arqueológicas en Constitución (Uhle 1915a); y del 15 mayo 1915, "Las piedras de tacitas" (Uhle 1915b) (cf. Rowe 1954:34-37).

${ }^{3}$ Otras ponencias en el Congreso de Americanistas de Buenos Aires dan cuenta de este giro, por ejemplo las de Aníbal Echeverría "Influencia incaica en el norte de Chile" y Tomás Guevara "Elementos estraños a los araucanos en el poema de Ercilla" (Lehmann-Nitsche 1912).

${ }^{4}$ Archivo del Instituto Iberoamericano de Berlin, Nachlass Uhle, Vortrag VIII [N.8035w 132]. 
